Istvan Vajtai $\cdot$ Rahel Sahli $\cdot$ Andreas Kappeler

Emanuel R. Christ $\cdot$ Rolf W. Seiler

\title{
Leiomyomatoid angiomatous neuroendocrine tumor (LANT) of the pituitary: a distinctive biphasic neoplasm with primitive secretory phenotype and smooth muscle-rich stroma
}

Received: 20 December 2005 / Accepted: 24 January 2006/Published online: 7 March 2006

(C) Springer-Verlag 2006

\begin{abstract}
We describe a hitherto undocumented variant of dimorphic pituitary neoplasm composed of an admixture of neurosecretory cells and profuse leiomyomatous stroma around intratumoral vessels. Radiologically perceived as a macroadenoma of $3.8 \mathrm{~cm}$ in diameter, this pituitary mass developed in an otherwise healthy 43-year-old female. At the term of a yearlong history of amenorrhea and progressive bitemporal visual loss, subtotal resection was performed via transsphenoidal microsurgery. Discounting mild hyperprolactinemia, there was no evidence of excess hormone production. Histologically, solid sheets, nests and cords of epithelial-looking, yet cytokeratin-negative cells were seen growing in a richly vascularized stroma of spindle cells. While strong immunoreactivity for NCAM, Synaptophysin and Chromogranin-A was detected in the former, the latter showed both morphological and immunophenotypic hallmarks of smooth muscle, being positive for vimentin, muscle actin and smooth muscle actin. Architectural patterns varied from monomorphous stroma-dominant zones through biphasic neuroendocrine-leiomyomatous areas, to pseudopapillary fronds along vascular cores. Only endothelia were labeled with CD34. Staining for S100 protein and GFAP,
\end{abstract}

I. Vajtai $(\bowtie) \cdot$ A. Kappeler

Institute of Pathology, University of Bern,

Murtenstrasse 31, Postfach 62,

3010, Bern, Switzerland

E-mail: istvanvajtai@yahoo.com

Tel.: + 41-31-6323210

Fax: + 41-31-6329938

R. Sahli · E. R. Christ

Department of Endocrinology,

University Hospital Bern, Bern,

Switzerland

R. W. Seiler

Department of Neurosurgery,

University Hospital Bern,

Bern, Switzerland characteristics of sustentacular cells, as well as bcl-2 and c-kit was absent. Except for $\alpha$-subunit, anterior pituitary hormones tested negative in tumor cells, as did a panel of peripheral endocrine markers, including serotonin, somatostatin, calcitonin, parathormone and vasoactive intestinal polypeptide. Mitotic activity was absent and the MIB-1 labeling index low (1-2\%). While assignment of this lesion to any established neoplastic entity is not forthcoming, we propose it is being considered as a lowgrade neuroendocrine tumor possibly related to null cell adenoma.

Keywords Pituitary adenoma Paraganglioma · Biphasic tumor $\cdot$ Stroma $\cdot$ Actin

\section{Introduction}

The variety of neoplasms and pseudotumoral entities encountered in and around the sella turcica reflects both the anatomical complexity of the skull base and the versatile functions of the pituitary proper $[1,4,12,19]$.

The majority of sellar mass lesions with endocrine phenotype are adenomas or hyperplasias originating from adenohypophyseal epithelial cells [4]. Very rarely, neuroepithelial (gangliocytic) elements of adenomatous tissue may participate, a constellation referred to as PANCH (pituitary adenoma with neuronal choristoma) [11]. In addition, sporadic examples of sellar paraganglioma, a neurosecretory tumor of the dispersed neuroendocrine system, are on record [15, 22, 24, 26, 28]. In either case, a handful of appropriately selected immunohistochemical markers, especially low molecular weight cytokeratin and synaptophysin as well as staining for pituitary hormones, usually allow for such processes to be assigned one of major, well-defined nosological categories [4].

In the following, we would like to share our experience with an intriguing biphasic neoplasm composed of cytokeratin-negative endocrine cells and prominent 
fusiform stroma with leiomyoma-like immunoreactivity. While comparable to either null cell adenoma or paraganglioma with respect to its neurosecretory element, the stromal moiety of this lesion offers a pattern not previously documented in such tumors. On the other hand, no analogy is forthcoming to recently defined spindle-cell neoplasms (pituicytoma, spindle-cell oncocytoma) of purported astrocytic or folliculostellate cell derivation either $[3,21]$.

\section{Case report}

\section{Clinical history and imaging}

The patient, a 43-year-old female, first consulted the Department of Endocrinology of the University Hospital Bern 2 years ago, reporting secondary amenorrhea and spontaneous galactorrhea. Except for mild arterial hypertension, anamnestic exploration was noncontributory. In particular, there was no evidence of extracranial malignant disease or a family history of phakomatosis or multiple endocrine neoplasia (MEN) syndrome. Laboratory testing revealed hyperprolactinemia of $120 \mu \mathrm{g} / \mathrm{l}$, as well as secondary hypogonadism. Cranial magnetic resonance imaging (MRI) confirmed the presence of a sellar space occupying lesion of $3 \times 3 \times 1.5 \mathrm{~cm}$, compatible with nonfunctioning pituitary macroadenoma. The patient then declined surgery and was administered oral dopaminergic medication with Cabergoline (Dostinex ${ }^{\circledR}$ ).

While this achieved relief of endocrine symptoms, perimetric assessment revealed gradual bitemporal visual field loss, indicating enlargement of the tumor at 1year interval. On preoperative MRI, the lesion measured $3.8 \times 3.2 \times 2.4 \mathrm{~cm}$, with para- and suprasellar extension (Fig. 1). Subtotal extirpation was performed via transsphenoidal approach. During surgery, the tumor was seen eroding the sphenoid bone and infiltrating both cavernous sinuses. Extensive adhesions to the optic chiasm prevented complete removal of the suprasellar part of the tumor. Postoperative recovery was uneventful, and no adjuvant radiotherapy administered.

\section{Materials and methods}

The surgical specimen, comprising several grayish white tissue fragments of a total volume of $1.5 \mathrm{~mm}^{3}$, was fixed in $4 \%$ buffered formalin, processed in paraffin and serially sectioned to $4 \mu \mathrm{m}$ thick slides. Histochemical stains included hematoxylin and eosin (H.E.), periodic acid-Schiff (PAS), van Gieson's elastic stain (EvG), Grimelius' chromaffin method and Gomori's reticulin (Ag).

For immunohistochemistry, dewaxed sections were pretreated either by boiling in $10 \mathrm{mM}$ citrate buffer $(\mathrm{pH}$ 6.0 ) or $10 \mathrm{mM}$ Tris-1 mM EDTA (pH 9.0) or by partial enzymatic digestion with $1 \mathrm{mg} / \mathrm{ml}$ trypsin 1:250 (Difco, Detroit, MI, USA). The sections were then (and following all subsequent steps) washed in Tris-buffered saline (TBS) and incubated with the primary antibody diluted in TBS with $0.5 \%$ casein and $5 \%$ normal goat serum, for $60 \mathrm{~min}$ at room temperature. The procedures for antigen retrieval and specification of primary antibodies are summarized in Table 1. Next, either a 1:300 dilution of biotinylated goat-anti-mouse immunoglobulin (Ig) or a 1:500 dilution of biotinylated goat-antirabbit Ig antiserum (depending on the species in which the primary antibody had been raised) was applied for $45 \mathrm{~min}$. Thereafter sections were incubated with streptavidin-biotin complex/alkaline phosphatase (1:200 in TBS) (DakoCytomation) for $45 \mathrm{~min}$. Finally, sections were developed with new fuchsin-naphtol AS-BI as chromogen (Sigma, St. Louis MO, USA) for $30 \mathrm{~min}$, counterstained with hematoxylin and mounted.
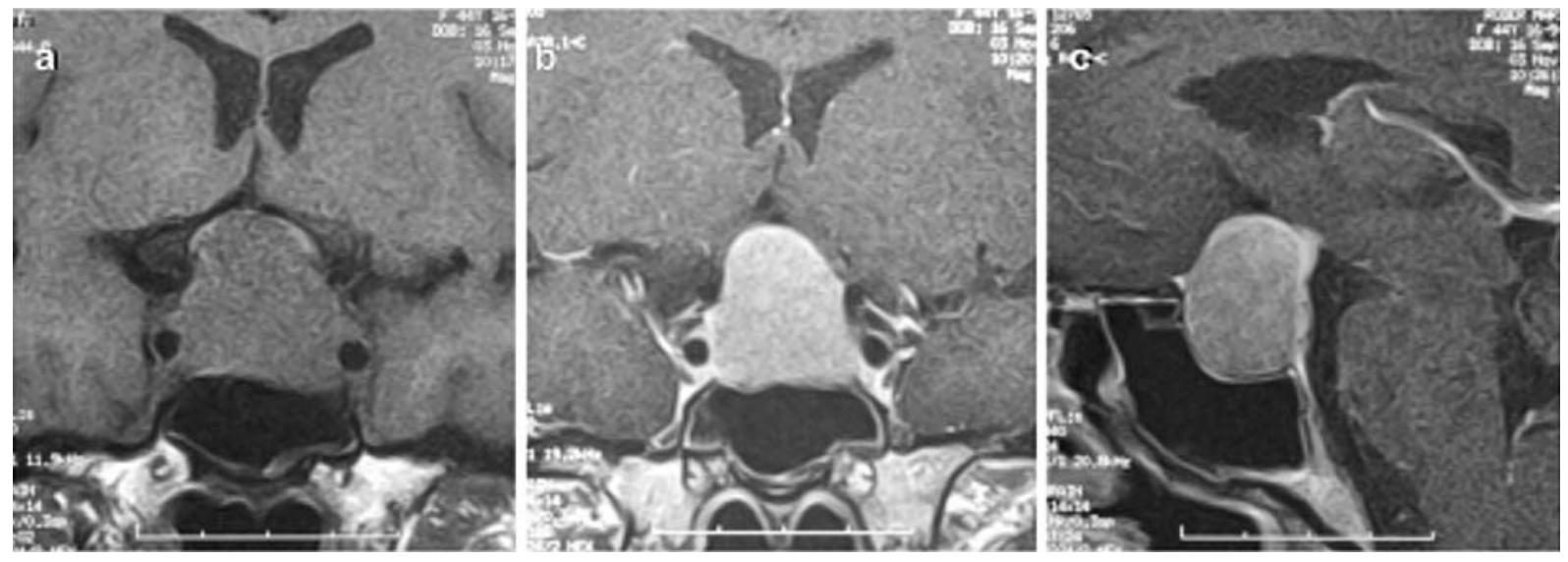

Fig. 1 Imaging characteristics of LANT. $T_{1}$ weighted frontal MRI scan (a) to show isointense pituitary tumor with suprasellar extension and partial encirclement of carotid arteries. On post- contrast frontal and sagittal sequences $(\mathbf{b}, \mathbf{c})$ there is marked homogenous enhancement of gadolinium. Infiltration of cavernous sinuses (b) and compression of chiasmatic cistern (c) are evident 
Table 1 Overview of primary antibodies for immunohistochemistry and antigen retrieval methods

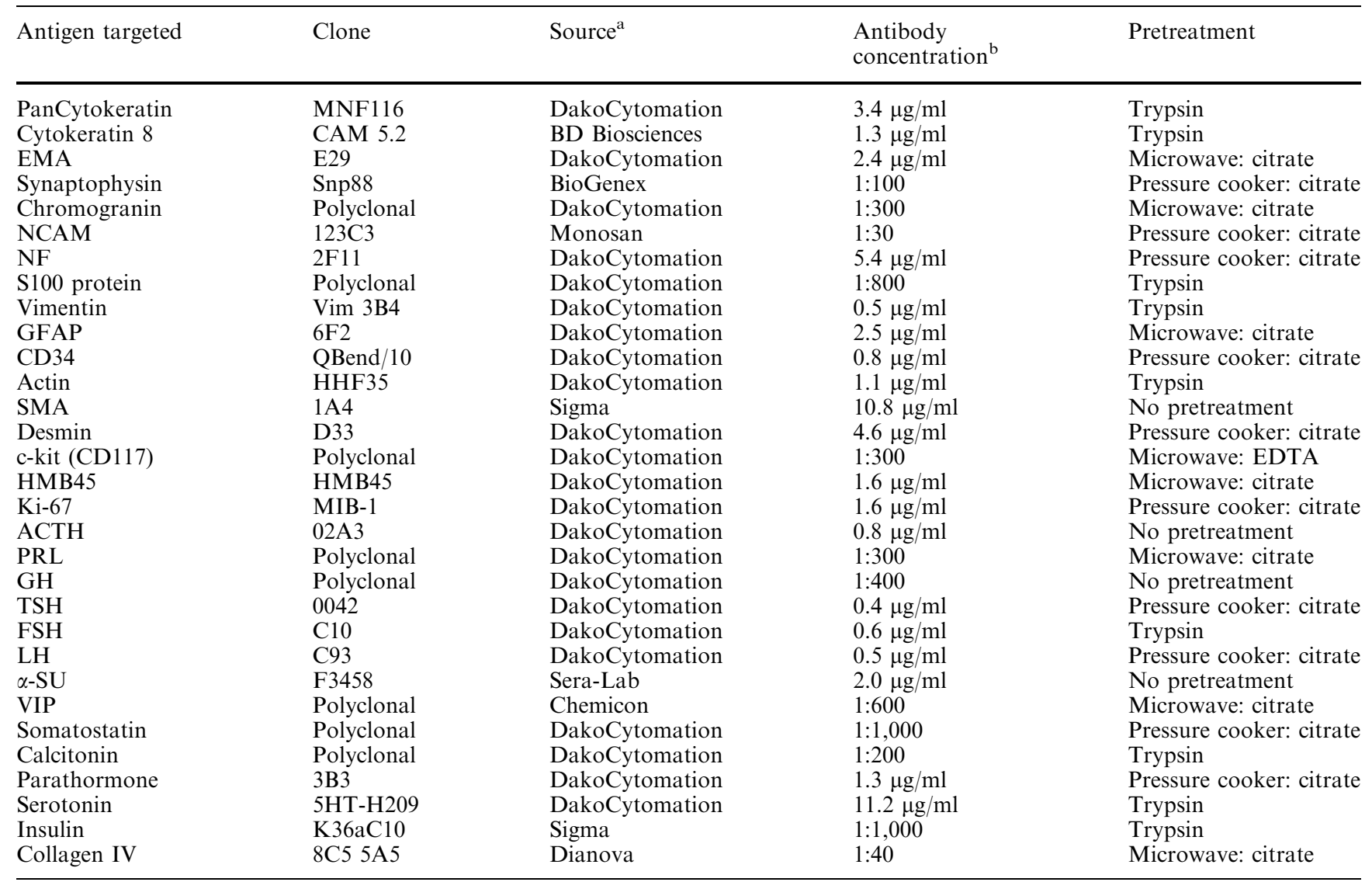

${ }^{a}$ DakoCytomation, Glostrup, Denmark; BD Biosciences, San Jose, CA, USA; BioGenex, San Ramon, CA, USA; Chemicon, Temecula, CA, USA; Dianova, Hamburg, Germany; Monosan, Uden, The Netherlands; Sera-Lab, Sussex, UK; Sigma, St. Louis, MO, USA ${ }^{b}$ Working concentrations are given where known; dilutions are indicated for polyclonal antibodies

\section{Pathological findings}

Microscopical examination showed a moderately cellular biphasic tumor, characterized by alternate epitheliallike cuboidal cells and fascicles of spindly stroma. The former tended to aggregate in solid sheets within slit-like spaces, often with nuclear crowding and peripheral shrinkage artifacts (Fig. 2a). Scattered nests of clear cells reminiscent of "Zellballen" - some of them confined within argyrophilic acini-were occasionally seen, while true paragangliomatous ribbons were absent. In between, stromal cells displayed bipolar cytoplasmic extensions individually ensheathed by basal lamina. Cigar-shaped nuclei were remarkably monomorphous and tended to lie centrally on cross-section profiles. The tumor was richly vascularized throughout, with cushions of stromal cells seemingly "budding" from adventitia (Fig. 2j, k). There were irregular transitions from compact stroma-predominant fields to papillary projections lined by a flattened layer of epithelial-like cells (Fig. 2b, c). Cellular atypia was absent in both components, as was significant mitotic activity; neither were there intratumoral regressive changes (necrosis).
On immunohistochemistry, the epithelial-like population displayed a rudimentary neurosecretory phenotype (Fig. $2 / \mathrm{d}-\mathrm{f}, 1)$, being strongly reactive for neural cell adhesion molecule (NCAM-CD56), synaptophysin and chromogranin-A and negative for neurofilament protein, epithelial membrane antigen (EMA) and cytokeratins, including the low molecular species cytokeratin 8 (CAM5.2). Except for $\alpha$-subunit, all major anterior pituitary hormones tested negative, as did a panel of peripheral endocrine markers (Fig. 2g). Most stromal cells were labeled with antibodies to vimentin and smooth muscle actin, with a significant proportion reacting for muscle actin as well (Fig. 2i, k). Staining for collagen type IV highlighted pericellular basal lamina. While endothelia consistently expressed CD34, only a small subset of stromal elements showed such positivity (Fig. 2h). Likewise, S100 protein immunoreactive cells, especially ones of sustentacular configuration, were absent. Reactions for bcl-2 and c-kit yielded negative results. No staining for the melanosomal marker HMB45 was detected. Occasional positive nuclei in both neurosecretory and stromal components randomly added up to a MIB- 1 count of less than $2 \%$. 

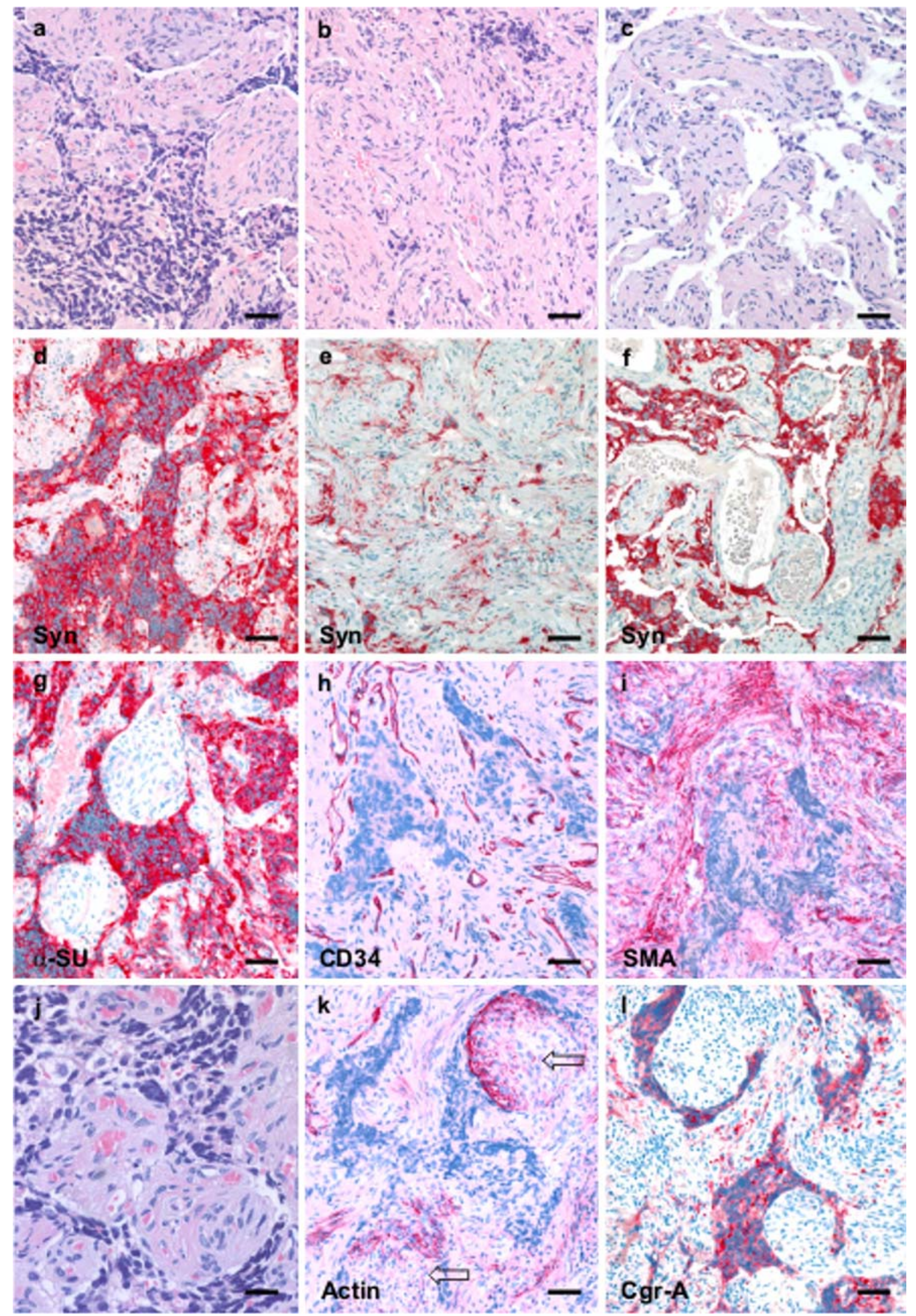
Fig. 2 Histology and immunophenotype of LANT. Biphasic architecture composed of solid nests of nondescript neuroendocrine cells with intervening bundles of fusiform stroma (a). Architectural patterns include transitions from hypocellular stroma-dominant zones (b) to papillary projections (c). Immunohistochemical detection of synaptophysin $(\mathbf{d}-\mathbf{f})$ indicates neuroendocrine phenotype of tumor cells. Different staining patterns are appreciated on corresponding sections from mixed neuroendocrine/mesenchymal (a, d), stroma-dominant (b, e) and papillary (c, f) areas. Only positivity for $\alpha$-subunit (g) suggests possible adenohypophyseal origin of tumor cells. Endothelia of intratumoral blood vessels are labeled with $C D 34$ (h), while intervening spindle cells are negative. Most of the latter show intense staining for smooth muscle actin on adjacent section plane (i). Organoid association of intratumoral arterioles and perivascular layers of smooth muscle cells (j) reminiscent of microvascular sphincter. Circumscribed "bud-like" compactions of stromal cells (k, $\mathbf{l}$, arrows) were often felt to result from such perivascular structures. Microphotographs not otherwise labeled represent H.E. stains. Except for "j" (40 $\mu \mathrm{m})$, bars correspond to $20 \mu \mathrm{m}$

\section{Discussion}

We describe a clinically nonfunctioning, low-grade, intrasellar neoplasm with biphasic composition, including neuroendocrine cells and leiomyomatous stroma. While metastatic origin could confidently be excluded on both clinical grounds and absence of any intrinsic sign of malignancy, the unique features of this neoplasm did not fit into any established neoplastic category indigenous to the sella either.

Albeit morphologically versatile, over $90 \%$ of pituitary adenomas, including those rare examples with neuronal metaplasia, consistently express cytokeratins, especially cytokeratin 8 [4]. While angiomatous vessels may occur in macroadenomas prone to apoplexy, these tend to be ectatic and thin-walled, rather than of angioleiomyomatous type. Conversely, spindle-cell pituitary lesions, i.e. granular cell tumor, as well as the recently introduced pituicytoma and spindle-cell oncocytoma, are monophasic in composition and lack evidence of neurosecretion [4]. Be they of purported Schwannian, astrocytic or folliculostellate cell descent, these uncommon neoplasms are labeled with antibodies to S100 protein and/or GFAP, staining for which was entirely absent in our case [3,21].

By virtue of it incorporating microvascular sphincterlike structures reminiscent of gomitoli bodies of the pituitary stalk, the present tumor further raised the differential diagnosis of glomangioma. However, akin to acral glomangiomas, those exceptional intrasellar occurrences on record reflect pericytic rather than neuroectodermal derivation of tumor cells $[2,8,9]$. We could identify a single case report of intrasellar leiomyoma [13]. Published prior to the routine use of immunohistochemistry, the figures accompanying that paper nevertheless depict an otherwise unremarkable, pure spindle-cell tumor.

A remote similarity to perivascular myomelanocytic tumor (PEComa) prompted us to perform immunohistochemistry for HMB45, which resulted negative [14].
When its prominent neuroendocrine features are given consideration, this tumor is further suggestive of paraganglioma $[15,18,22,24,26,28]$. Indeed, detection of synaptophysin and/or chromogranin-A has commonly been relied on to identify both these neoplasms of the dispersed neuroendocrine system and pituitary adenomas [4, 23]. Only a minority of extraadrenal paragangliomas are functioning, with catecholamines, serotonin and vasoactive intestinal polypeptide (VIP) being the most frequent secretory products. While commonly encountered in gonadotroph cell adenomas and the so-called null cell adenomas, immunoreactivity for $\alpha$-subunit, as seen in our case, may exceptionally occur in paragangliomas as well $[4,5]$. Not only are primary intrasellar paragangliomas exceedingly rare but also we are unable to identify any previous bona fide example with mixed neurosecretory-leiomyomatous pattern, irrespective of location.

The rather speculative issue of a solitary fibrous tumor (SFT) colliding with or an inflammatory pseudotumor permeating the stroma of a null cell adenoma or paraganglioma was excluded by the absence of CD34 immunoreactivity in most spindle cells other than endothelia [1,6]. An extensive search of the literature yielded a single reference to a case of vaginal leiomyoma with intratumoral paraganglion cells [17]. While these likely originated from intramural paraganglia, possibly with secondary hyperplasia, no such structures are normally present in the pituitary.

Developmental remnants of the neural crest at the skull base are considered the most likely source of intrasellar paragangliomas [22]. Horvath et al. [11] discussed "lineage infidelity" of adenohypophyseal epithelium to account for the occurrence of hybrid adenomatousneuronal (gangliocytic) pituitary tumors. In a similar vein, folliculostellate cells have been considered as a possible neoplastic reservoir with stem cell properties [21]. Though such dysontogenetic concepts may be all accommodating, the actual morphogenesis of stromal spindle cells in our case remains speculative. These may, for instance, represent but a variant of otherwise well-known florid microvascular proliferation in endocrine neoplasia, with grotesque overgrowth of adventitial smooth muscle [7, 16, 25]. Conversely, neuroepithelial tumor cells may have undergone myogenic metaplasia. A similar phenomenon has been known to occur in some tumors of the nervous system of both glial and neural crest derivation-including benign lesions [27]. Along the same line, an origin from pluripotential neural crest cells with dual stromal/neurosecretory commitment is also plausible. A neoplastic phenotype of this kind has indeed been documented in gastrointestinal stromal tumors (GISTs) of the Carney triad [10, 20]. Conspicuously, affected individuals tend to develop paragangliomas as well. At variance from GISTs, however, spindle cells in the present case failed to react for c-kit, and the patient did not present any clinical evidence of the Carney triad either.

We interpret our findings as a peculiar form of low-grade, dimorphic neuroendocrine neoplasm with 
prominent stromal component. Being cytokeratin negative and showing only a rudimentary secretory phenotype, the epithelial-looking component may not allow for definite histogenetic classification into adenohypophyseal or neuroepithelial in nature. The descriptive diagnosis "leiomyomatoid angiomatous neuroendocrine tumor" (LANT) is therefore proposed to address both the conspicuous stroma and the noncommittal morphology of the secretory element of the tumor. This serendipitous observation awaits confirmation by additional reports.

Acknowledgments We wish to thank Professor Markus Tolnay (Institute of Neuropathology, University Hospital Basel, Switzerland), Drs. Zsuzsanna Varga, Aurel Perren (Institute of Clinical Pathology, University Hospital Zürich) and Frank Heppner (Institute of Neuropathology, University Hospital Zürich, Switzerland) for the critical review of the slides. The immunohistochemical reactions referred to in this study are the work of Mrs. Eva Bähler, Micaela Güdel, Christine Steffen and Christiane Steinger.

\section{References}

1. Al-Shraim M, Syro LV, Kovacs K, Estrada H, Uribe H, AlGahtany M (2004) Inflammatory pseudotumor of the pituitary: case report. Surg Neurol 62:264-267

2. Argos MD, Ruiz A, Sanchez F, GarciaAsa SL, Kovacs K, Horvath E, Ezrin C, Weiss MH (1984) Sellar glomangioma. Ultrastruct Pathol 1:49-54

3. Brat DJ, Scheithauer BW, Staugaitis SM, Holtzman RN, Morgello S, Burger PC (2000) Pituicytoma: a distinctive lowgrade glioma of the neurohypophysis. Am J Surg Pathol 24:362-368

4. Burger PC, Scheithauer BW, Vogel FS (2002) Region of the sella turcica. In: Surgical pathology of the nervous system and its coverings, 4th ed. Churchill Livingstone, Philadelphia, pp 437-497

5. Canda AE, Sis B, Sokmen S, Fuzun M, Canda MS (2004) An unusual mesenteric paraganglioma producing human chorionic gonadotrophin. Tumori 90:249-252

6. Carneiro SS, Scheithauer BW, Nascimento AG, Hirose T, Davis DH (1996) Solitary fibrous tumor of the meninges: a lesion distinct from fibrous meningioma. A clinicopathologic and immunohistochemical study. Am J Clin Pathol 106:217224

7. Gaudin PB, Rosai J (1995) Florid vascular proliferation associated with neural and neuroendocrine neoplasms. A diagnostic clue and potential pitfall. Am J Surg Pathol 19:642-652

8. Granter SR, Badizadegan K, Fletcher CD (1998) Myofibromatosis in adults, glomangiopericytoma, and myopericytoma: a spectrum of tumors showing perivascular myoid differentiation. Am J Surg Pathol 22:513-525

9. Hänggi D, Adams H, Hans VH, Probst A, Tolnay M (2005) Recurrent glomus tumor of the sellar region with malignant progression. Acta Neuropathol (Berl) 110:93-96

10. Horenstein MG, Hitchcock TA, Tucker JA (2005) Dual CD117 expression in gastrointestinal stromal tumor (GIST) and paraganglioma of Carney triad: a case report. Int J Surg Pathol 13:87-92
11. Horvath E, Kovacs K, Scheithauer BW, Lloyd RV, Smyth HS (1994) Pituitary adenoma with neuronal choristoma (PANCH): composite lesion or lineage infidelity? Ultrastruct Pathol 18:565-574

12. Kleinschmidt-DeMasters BK, Mierau GW, Sze CI, Breeze RE, Greffe B, Lillehei KO, Stephens JK (1998) Unusual dural and skull-based mesenchymal neoplasms: report of four cases. Hum Pathol 29:240-245

13. Kroe DJ, Hudgins WR, Simmons JC, Blackwell CF (1968) Primary intrasellar leiomyoma. Case report. J Neurosurg 29:189-191

14. Lehman NL (2004) Malignant PEComa of the skull base. Am J Surg Pathol 28:1230-1232

15. Mokry M, Kleinert R, Clarici G, Obermayer-Pietsch B (1998) Primary paraganglioma simulating pituitary macroadenoma: a case report and review of the literature. Neuroradiology 40:233-237

16. Moran CA, Suster S (1999) Angiomatoid neuroendocrine carcinoma of the thymus: report of a distinctive morphological variant of neuroendocrine tumor of the tumor resembling a vascular neoplasm. Hum Pathol 30:635-639

17. Naidoo P (2000) Vaginal leiomyoma with heterologous paragangliomatous elements. Int J Surg Pathol 8:359-365

18. Paulus W, Jellinger K, Brenner H (1989) Melanotic paraganglioma of the orbit: case report. Acta Neuropathol (Berl) 79:340-346

19. Paulus W, Honegger J, Keyvani K, Fahlbusch R (1999) Xanthogranuloma of the sellar region: a clinicopathological entity different from adamantinomatous craniopharyngioma. Acta Neuropathol (Berl) 97:377-382

20. Perez-Atayde AR, Shamberger RC, Kozakewich HW (1993) Neuroectodermal differentiation of the gastrointestinal tumors in the Carney triad. An ultrastructural and immunohistochemical study. Am J Surg Pathol 17:706-714

21. Roncaroli F, Scheithauer BW, Cenacchi G, Horvath E, Kovacs K, Lloyd RV, Abell-Aleff P, Santi M, Yates AJ (2002) "Spindle cell oncocytoma" of the adenohypophysis. A tumor of folliculostellate cells? Am J Surg Pathol 26:1048-1055

22. Sambaziotis D, Kontogeorgos G, Kovacs K, Horvath E, Levedis A (1999) Intrasellar paraganglioma presenting as nonfunctioning pituitary adenoma. Arch Pathol Lab Med 123:429-432

23. Scheithauer BW, Nora FE, LeChago J, Wick MR, Crawford BG, Weiland LH, Carney JA (1986) Duodenal gangliocytic paraganglioma. Clinicopathologic and immunohistochemical study of 11 cases. Am J Clin Pathol 86:559-565

24. Scheithauer BW, Parameswara A, Burdick B (1996) Intrasellar paraganglioma: report of a case in a sibship of von HippelLindau disease. Neurosurgery 38:395-399

25. Shin WY, Groman GS, Berkman JI (1977) Phaeochromocytoma with angiomatous features. A case report and ultrastructural study. Cancer 40:275-283

26. Steel TR, Dailey AT, Born D, Berger MS, Mayberg MR (1993) Paragangliomas of the sellar region: report of two cases. Neurosurgery 32:844-847

27. Van Dorpe J, Sciot R, De Vos R, Uyttebroeck A, Stas M, Van Damme B (1997) Neuromuscular choristoma with smooth and striated muscle component: case report with immunohistochemical and ultrastructural analysis. Am J Surg Pathol 21:1090-1095

28. Yokoo H, Tanaka G, Isoda K, Hirato J, Nakazato Y, Fujimaki H, Watanabe K, Saito N, Sasaki T (2003) Novel crystalloid structures in suprasellar paraganglioma. Clin Neuropathol 22:222-228 